\title{
Un proyecto europeo digitaliza la memoria de la arqueología experimental para su conservación
}

El origen del proyecto europeo Retold, liderado por la asociación internacional EXARC, es el interés de conservar el patrimonio que generan los museos de arqueología al aire libre con la creación de un sistema estandarizado de recopilación, digitalización y difusión de su conocimiento (su memoria) sobre los procesos de reconstrucción de edificios y productos de elaboración artesanal. El proyecto tiene una duración de cuatro años (enero 2021 a diciembre de 2024) y se concreta en la creación de una plataforma donde se almacenarán estas memorias en formato digital, disponibles tanto para el personal técnico de esta tipología de espacios, como para la creación de narrativas (storytelling) para el público no especializado.

Paloma González Marcén, Clara Masriera Esquerra | Centre d'Estudis del Patrimoni Arqueològic (CEPARQ), Universitat Autònoma de Barcelona (UAB)

URL de la contribución <http://www.iaph.es/revistaph/index.php/revistaph/article/view/4884>

\section{La memoria de la experiencia en arqueología experimental}

Los años sesenta y setenta del siglo XX representan un punto de inflexión en la disciplina arqueológica. En el caso que nos ocupa, en este período surgen diversas iniciativas en los países europeos de tradición anglosajona, que vieron en la experimentación y reconstrucción de los procesos artesanales y constructivos en la antigüedad una vía para ampliar el conocimiento del pasado. Los dos ejemplos más emblemáticos que nacieron en aquel entonces fueron, por una parte, la creación del museo de arqueología al aire libre, la Butser Ancient Farm, de la mano del arqueólogo Peter J. Reynolds (1939-2001) y Christine Shaw, así como el Lejre Experimental Centre (actualmente Sagnlandet Lejre), que fue fundado por el etnólogo Hans-Ole Hansen (1939) en los años sesenta en Dinamarca.

A lo largo de más de medio siglo, la arqueología experimental se ha ido definiendo como una subdisciplina dentro de la arqueología, que tiene como finalidad conocer los procesos de elaboración de la cerámica, la talla de piedra sílex, el trabajo del metal, de los tejidos, etc. así como los procesos de construcción de las casas y reconstrucción de cementos para conocer las técnicas de construcción. Estas experiencias, basadas en la práctica artesanal, apenas se han divulgado o publicado de forma sistemática, por lo cual su recuerdo se ha ido perdiendo a medida que las personas que las llevaron a cabo han ido desapareciendo.

A principios del siglo $X X I$ se crea la red internacional de patrimonio EXARC, liderada por Roeland $P$. Paardekooper, con el apoyo de muchas personas y organizaciones vinculadas a la arqueología experimental, para organizar y visibilizar el conocimiento generado en torno a los museos de arqueología al aire libre y los procesos de arqueología experimental. Esta organización ha conseguido aglutinar en una red colaborativa todos estos espacios existentes en todo el mundo, principalmente en Europa, y ha trabajado incansablemente, sobre todo a través de las conferencias anuales de arqueología experimental, para dar a conocer y ordenar todo el conocimiento que surge de estos equipamientos y sus investigaciones.

Desde hace unos veinte años, la organización EXARC ha liderado diversos proyectos europeos que han permitido dar a conocer los museos de arqueología al aire libre y sus actividades experimentales, tanto en su carácter de espacios vivenciales y singulares de relación entre la arqueología y el público como en su aportación a la investigación científica desde la experimentación. En este contexto es cuando, a partir del año 2019, se 


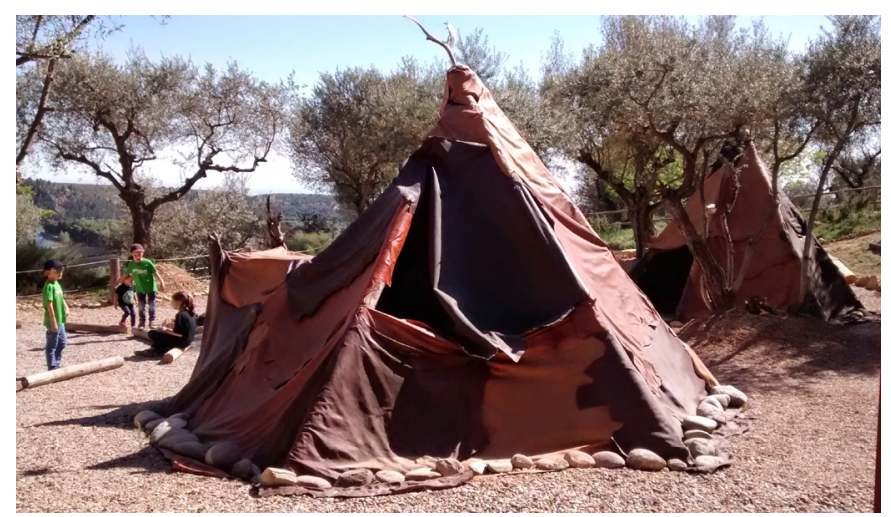

Parque arqueológico que forma parte del Campus de Arqueología de la UAB en La Noguera | foto Campus d'Arqueologia de la Noguera

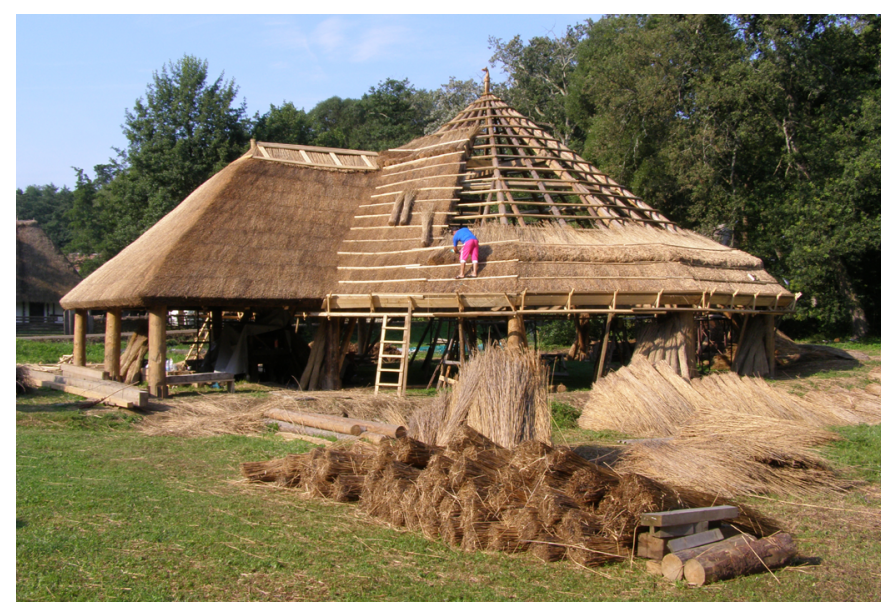

Casa reconstruida en el complejo Astra de Romania, socio del proyecto | foto ASTRA Museum

empieza a plantear la necesidad urgente de recopilar toda aquella información derivada de los experimentos artesanales y de construcción. La naturaleza de esta información ha sido básicamente oral, forma parte de la memoria de las personas que han iniciado y participado de los experimentos, pero no ha sido nunca recogida, o muy pocas veces, hecho que hace que peligre gran parte del conocimiento obtenido en estas últimas décadas en los parques arqueológicos al aire libre.

Es esta situación la que nos hizo diseñar un proyecto, el proyecto RETOLD, liderado por la asociación internacional EXARC, para crear un sistema estandarizado de recopilación, digitalización y difusión del conocimiento sobre los procesos de reconstrucción de edificios y tra-

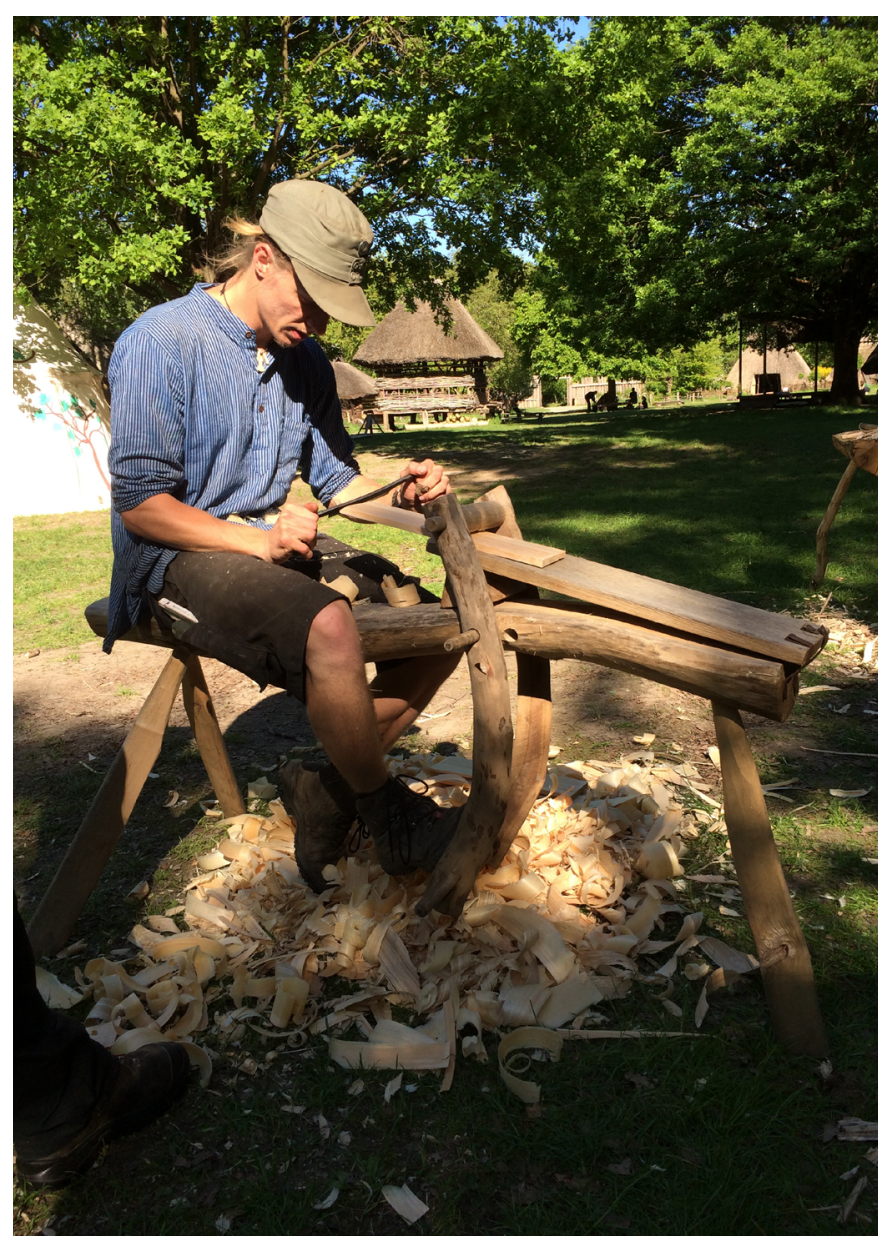

Proceso artesanal de arqueología experimental en el museo al aire libre de Berlín, socio del proyecto | foto Düppel Museo

diciones que realizan los museos de arqueología al aire libre. El proyecto tiene una duración de cuatro años (enero 2021 a diciembre de 2024) y un presupuesto de unos $300.000,00 €$. Durante este período, se desarrollarán métodos de documentación multimodal que acercarán el pasado al público general mediante narraciones digitales inmersivas.

El proyecto está formado por seis socios. Tres socios son museos de arqueología al aire libre: dos situados en Alemania, el Steinzeit Park Dithmarschen en la población alemana de Albersdorf (Schleswig-Holstein) y el Düppel Museum que depende de la fundación Stadtmuseum de Berlín; y el ASTRA National Museum Complex de Rumanía. Los tres socios restantes son 
EXARC, ubicado en los Países Bajos, como socio promotor y coordinador, con un papel importante en el apartado de comunicación, y Nüwa Digital Media Content Production, ubicada en Irlanda, agencia especializada en producción de estrategias digitales para el sector cultural. Finalmente, el socio académico está representado por el Centre d'Estudis del Patrimoni Arqueològic (CEPARQ) de la Universitat Autònoma de Barcelona $(U A B)^{1}$ que, junto con los dos últimos socios, tiene la función de coordinar el sistema digital y la base de datos de los contenidos digitales que se recopilarán procedentes de los museos del proyecto.

\section{Un repositorio europeo de los museos de arqueología al aire libre}

Retold quiere ser el repositorio europeo de los museos de arqueología al aire libre (MAAL). Los objetivos del proyecto son:

$>$ Desarrollar un flujo de trabajo estandarizado para recoger, digitalizar y compartir datos relacionados con la reconstrucción experimental de edificios, artesanías $\mathrm{y}$ tradiciones.

$>$ Crear un repositorio digital de acceso abierto con la finalidad que los profesionales de los museos, las personas investigadoras y el público pueda acceder libremente a estos datos.

> Producir narraciones de historias en los museos que sean más atractivas e impactantes para el público general, al mismo tiempo que cuenten con una base científica de calidad.

¿Y cómo se alcanzarán estos objetivos? En el espacio temporal de 2021 a 2024 se llevarán a cabo diferentes acciones focalizadas en resolver los objetivos propuestos. En 2021 se está trabajando en unas primeras encuestas que ayudarán a conocer aquellos documentos digitalizados que ya poseen los museos (MAAL) y concretar las necesidades, a nivel de digitalización, que presentan estos espacios. Paralelamente, se está trabajando a nivel tecnológico para conocer la mejor herramienta digital para albergar toda esta información y organizarla mediante etiquetas y seguidores de voz,

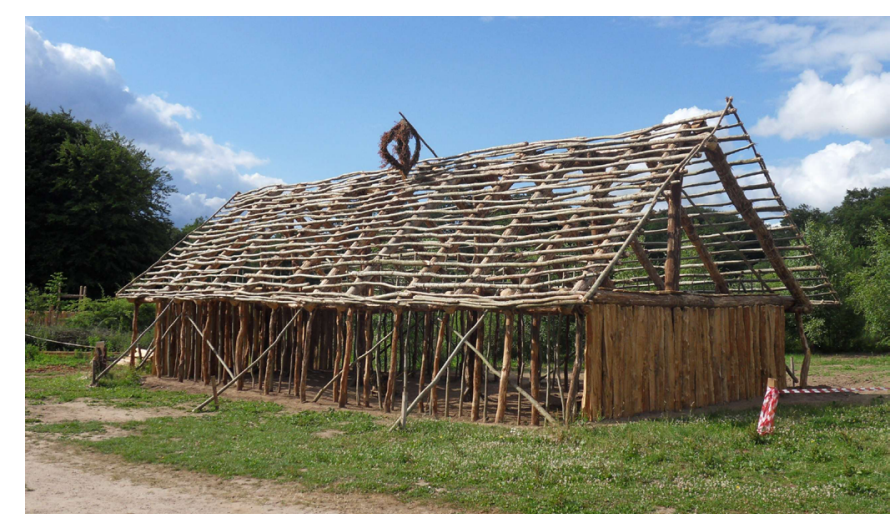

Proceso de reconstrucción de una casa del Bronce Final-primera Edad del Hierro en Steinzeit Park Dithmarschen (Albersdorf, Alemania), socio del proyecto | foto Steinzeitpark Dithmarschen

texto, imagen estática y en movimiento. Durante el transcurso de todo el proyecto, se realizarán seminarios de formación, reuniones de coordinación de los socios y actividades de divulgación del mismo proyecto.

En 2024, se espera poder tener en marcha una primera versión de la plataforma, que integrará el repositorio de datos relacionados con la reconstrucción experimental de edificios y procesos de elaboración de productos artesanales de la antigüedad. Esta primera versión será presentada públicamente al resto de museos de arqueología al aire libre, mediante la red internacional EXARC, para ampliar los contenidos presentes en la misma.

\section{NOTAS}

1. En la Universitat Autònoma de Barcelona el proyecto está vinculado al Máster en Humanidades y Patrimonio Digital que se ha iniciado en el curso 2020-2021. 